ISSN 0103-9954

\title{
EMERGÊNCIA E DESENVOLVIMENTO INICIAL DE PLÂNTULAS DE Cassia grandis L. f. EM FUNÇÃO DE DIFERENTES SUBSTRATOS
}

\author{
EMERGENCY AND INITIAL DEVELOPMENT OF Cassia grandis L. f. PLANTS ACCORDING TO \\ DIFFERENT SUBSTRATES
}

\author{
Caio César Pereira Leal ${ }^{1}$ Salvador Barros Torres ${ }^{2}$ Aldiclebson Augusto Fernandes de Brito ${ }^{3}$ \\ Rômulo Magno Oliveira de Freitas ${ }^{4}$ Narjara Walessa Nogueira ${ }^{5}$
}

\begin{abstract}
RESUMO
Atualmente, busca-se utilizar substratos constituídos, principalmente, de resíduos orgânicos, a fim de diminuir os custos com adubação química. Nesse sentido, o experimento teve como objetivo avaliar diferentes tipos de substratos para a emergência e desenvolvimento inicial de plântulas de cássia-rosa (Cassia grandis L. f.). O experimento foi conduzido em casa de vegetação do Departamento de Ciências Vegetais da Universidade Federal Rural do Semiárido (UFERSA), em Mossoró - RN, no período de abril a maio de 2012. Os substratos utilizados foram: terra vegetal + palha de arroz (nas proporções de 1:1, 1:3 e 3:1), terra vegetal + pó de madeira (nas proporções de 1:1, 1:3 e 3:1), terra vegetal + fibra de coco (nas proporções de 1:1, 1:3 e 3:1), terra vegetal + casca de castanha-de-caju (nas proporções de 1:1, 1:3 e 3:1) e terra vegetal (testemunha). O delineamento estatístico utilizado foi o inteiramente casualizado, com 13 tratamentos (combinações dos substratos), em quatro repetições de 25 sementes e as médias submetidas ao teste de Skot-knott $(\mathrm{pr}<0,05)$. Foram avaliadas as variáveis porcentagem e velocidade de emergência, comprimento da parte aérea, comprimento de raiz e massa seca da parte aérea, massa seca da raiz e massa seca total. De acordo com os resultados, os substratos terra vegetal + pó de madeira (1:1) e terra vegetal + fibra de coco (1:3) foram os mais apropriados, proporcionando melhores resultados em emergência, massa seca da parte aérea, comprimento da parte aérea, massa seca da raiz e comprimento da raiz. Por outro lado, verificou-se que o substrato composto com terra vegetal e casca de castanha-de-caju (1:3) mostrou-se inadequado para a emergência de plântulas de cássia-rosa.
\end{abstract}

Palavras-chave: Cassia grandis; sementes; produção de mudas.

\section{ABSTRACT}

Currently, it is aimed to use substrates composed primarily of organic waste in order to reduce costs with chemical fertilizer. In that sense, the experiment was to evaluate different types of substrates for the emergence and early development of seedlings of Cassia grandis L. f. The experiment was carried out in a greenhouse at the Departament of Vegetable Sciences of Federal Rural do Semi-Árido (UFERSA), in Mossoró, Rio Grande do Norte state, Brazil. The substrates used were: sand + carbonized rice husk (in ratios of 1:1, 1:3 and 3:1), plant sand + wood dust (in ratios of 1:1, 1:3 and 3:1), plant sand + coconut fiber (in ratios of 1:1, 1:3 and 3:1), plant sand + chestnut bark (in ratios of 1:1,1:3 and 3:1) and plant sand

1 Engenheiro Agrônomo, Msc., Doutorando do Programa de Pós-Graduação em Fitotecnia, Universidade Federal Rural do Semi-Árido, BR-110, Km 47, CEP 59625-900, Mossoró (RN), Brasil. caioleal3@hotmail.com

2 Engenheiro Agrônomo, Dr., Professor Colaborador da Universidade Federal Rural do Semi-Árido e Pesquisador da Empresa de Pesquisa Agropecuária do Rio Grande do Norte, BR-110, Km 47, CEP 59625-900, Mossoró (RN), Brasil.sbtorres@ufersa.edu.br

3 Engenheiro Agrônomo, Msc., Programa de Pós-Graduação em Manejo de Solo e Água, Universidade Federal Rural do Semi-Árido, BR-110, Km 47, CEP 59625-900, Mossoró (RN), Brasil. aldiclebson@hotmail.com

4 Engenheiro Agrônomo, Msc., Doutorando do Programa de Pós-Graduação em Fitotecnia, Universidade Federal Rural do Semi-Árido, BR-110, Km 47, CEP 59625-900, Mossoró (RN), Brasil. romulomagno_23@hotmail.com

5 Engenheiro Agrônomo, Msc., Doutorando do Programa de Pós-Graduação em Fitotecnia, Universidade Federal Rural do Semi-Árido, BR-110, Km 47, CEP 59625-900, Mossoró (RN), Brasil. walessinha@hotmail.com

Recebido para publicação em 5/05/2013 e aceito em 7/10/2014

Ci. Fl., v. 26, n. 3, jul.-set., 2016 
(control). The experimental design was a completely randomized design with 13 treatments (combinations of substrates), with four replications of 25 seeds and the means to test for Skot-knot ( $\mathrm{pr}<0.05)$. We evaluated the following variables: plant emergence, emergence speed, plant height, root length and weight of the aerial part of the plant, root dry mass and total dry mass. According to the results, the substrate plant sand + sawdust $(1: 1)$ and plant sand + coconut fiber (1:3) showed higher values, providing better results in emergence, weight of the aerial part of the plant, length of the aerial part of the plant, root dry mass and root length. It was found that the substrate compounds sand plant and chestnut bark (1:3) is harmful to the emergence of seedling of Cassia grandis.

Keywords: Cassia grandis; seeds; seedling production.

\section{INTRODUÇÃO}

A Cassia grandis L. f. pertence à família Fabaceae - caesalpinoideae é comumente conhecida como, cássia-grande ou cássia-rosa, com ocorrência desde a região amazônica até o pantanal matogrossense. É uma árvore que pode atingir de 15 a 20 $\mathrm{m}$ de altura, apresenta copa ampla, tronco revestido por casca acinzentada, possui grande potencial ornamental, podendo ser usada em paisagismo. No uso medicinal é popularmente utilizada para preparo de xaropes, tratamento de infecções dermatológicas e antimicótica (CÁCERES et al., 1995; LORENZI, 2008). Diante dessas utilidades, ainda são poucos os estudos envolvendo a produção de mudas dessa espécie, bem como a avaliação do seu potencial silvicultural e econômico.

Atualmente, o mercado exige que o custo em qualquer atividade seja o menor possível. No tocante à produção de mudas, buscam-se cada vez mais substratos alternativos, a fim de diminuir os custos dessa operação. A necessidade de utilizar substratos melhores se dá pelo fato de que para uma boa germinação de um determinado lote de sementes é necessário que as mesmas sejam colocadas em um meio que lhe ofereça condições adequadas de luz, umidade, densidade e oxigênio (ARAÚJO e PAIVA SOBRINHO, 2011). Ainda, segundo estes autores, é importante conhecer a característica física do substrato, uma vez que uma densidade muito alta, por exemplo, poderá limitar o crescimento da muda.

Além de boa qualidade física, os substratos também devem apresentar quantidade de nutrientes adequadas para promover o bom desenvolvimento da muda, elementos esses que muitas vezes oneram o custo de produção. Nesse sentido, busca-se a utilização por substratos constituídos, principalmente, de resíduos orgânicos, a fim de diminuir os custos com adubação química (MORAES NETO et al., 2003). Entre esses, encontra-se a casca de arroz carbonizada, cujo resíduo da agroindústria processadora de arroz é disponível em grandes quantidades na região do Alto Oeste do estado do Rio Grande do Norte. Portanto, a possibilidade de ser utilizada por produtores com baixo poder de investimento na composição de substratos comerciais, sugere a necessidade de avaliar esse material como componente de substratos alternativos (SAIDELLES et al., 2009).

Outro substrato bastante utilizado e que vem sendo bastante comercializado para esse fim, é a fibra de coco. Essa fibra de coco, quase inerte quimicamente, possui característica física de alta porosidade, sendo obtida através de diversas operações como corte, desfibramento, secagem, trituração, lavagem e, quando necessário, compostagem (CARRIJO et al., 2002).

Outra boa alternativa na composição de substratos, na região Oeste potiguar, é a casca de castanha-de-caju, pela sua grande disponibilidade, principalmente, no município de Serra do Mel $\mathrm{RN}$, como evidenciado por Correia et al. (2005) que utilizaram o tegumento da amêndoa do caju decomposto na produção de porta-enxerto de goiabeira e obtiveram resultados satisfatórios na agregação desse substrato às raízes. Com base nesses aspectos, o substrato deve ser o primeiro item a ser planejado no processo de produção de mudas de boa qualidade, caso contrário pode ocasionar irregularidade ou até mesmo nulidade na germinação (ARAÚJO e PAIVA SOBRINHO, 2011).

Diante do exposto, o presente trabalho teve como objetivo avaliar substratos alternativos na emergência e desenvolvimento inicial de plântula de Cassia grandis L. f.

\section{MATERIAL E MÉTODOS}

Sementes de Cassia grandis L. f., foram coletadas em áreas de mata atlântica, localizadas no 
município de Moreno, $\mathrm{PE}\left(8^{\circ} 07^{\prime} 07^{\prime} \mathrm{S}, 35^{\circ} 05^{\prime} 32^{\prime \prime O}\right.$ e $96 \mathrm{~m}$ de altitude), no período de outubro a dezembro de 2011. Após a coleta, as vagens foram levadas para o laboratório de análises de sementes da Universidade Federal Rural do Semiárido, Mossoró - RN, onde as sementes foram extraídas com auxílio de um martelo. As sementes foram colocadas para secar à sombra, em seguida, acondicionadas em embalagem de papel e armazenadas em ambiente controlado $\left(16^{\circ} \mathrm{C}\right.$ e $45 \%$ de umidade relativa do ar) até o início da fase experimental.

Antes da semeadura efetuou-se o desponte da semente na região distal do embrião, utilizandose tesoura de poda e, em seguida, foram colocadas para embeber em água por 24 horas, conforme recomendação de Carvalho Filho (2002).

A semeadura se deu em bandejas de plástico de 50 células $(100 \mathrm{ml})$, dispostas em casa de vegetação, com irrigação diária, utilizando-se as seguintes composições de substratos: 1) terra vegetal + casca de arroz carbonizada $(1: 1) ; 2)$ terra vegetal + casca de arroz carbonizada $(1: 3) ; 3)$ terra vegetal + casca de arroz carbonizada $(3: 1) ; 4)$ terra vegetal + pó de madeira $(1: 1) ; 5)$ terra vegetal + pó de madeira $(1: 3) ; 6)$ terra vegetal + pó de madeira $(3: 1) ; 7)$ terra vegetal + fibra de coco $(1: 1) ; 8)$ terra vegetal + fibra de coco $(1: 3) ; 9)$ terra vegetal + fibra de coco $(3: 1) ; 10)$ terra vegetal + casca de castanha $(1: 1)$; 11) terra vegetal + casca de castanha $(1: 3)$; 12) terra vegetal + casca de castanha (3:1) e 13) terra vegetal (testemunha), cujas caracterizações físicas e químicas encontram-se na Tabela 1.

As variáveis avaliadas são descritas a seguir:

Emergência - Foram utilizadas 100 sementes por tratamento, divididas em quatro subamostras de 25 sementes, com irrigação diária, utilizando-se as diversas composições de substratos. As contagens do número de plântulas emergidas iniciaram-se aos três dias e estenderam-se até aos 20 dias após a semeadura. As plântulas foram avaliadas de acordo com os critérios adotados para avaliação da parte aérea de plântulas em um teste de germinação (BRASIL, 2009). Os resultados foram expressos em porcentagem média de emergência para cada tratamento.

Velocidade de emergência - realizada concomitantemente ao teste de emergência, sendo realizadas contagens diárias, do primeiro ao vigésimo dia, de plântulas normais, e os cálculos executados seguindo fórmula proposta por Edmond e Drapala (1958).

Altura de plântulas e comprimento de raiz
- no final do teste de emergência, cinco plântulas de cada unidade experimental foram medidas com auxílio de uma régua graduada em centímetros; para o comprimento da raiz, tomou-se a medida da base do colo a extremidade da raiz e, para a parte aérea, mediu-se da base do colo ao ápice da plântula, sendo os resultados expressos em centímetros.

Massa seca da parte aérea e da raiz - as cinco plantas utilizadas para avaliar o comprimento foram fragmentadas e postas para secar em estufa de circulação de ar forçado, regulada a $65^{\circ} \mathrm{C}$ até atingirem peso constante, sendo posteriormente pesadas em balança de precisão $(0,001 \mathrm{~g})$, para avaliação da matéria seca da parte aérea, da raiz e total.

O delineamento estatístico utilizado foi o inteiramente casualizado, com 13 tratamentos (combinações dos substratos), cada um com quatro unidades experimentais com 25 sementes cada. Os resultados foram submetidos à análise de variância, utilizando-se o software SISVAR 3.01 (FERREIRA, 2008). Na análise e avaliação dos ensaios foi empregado o teste de Skot-knott $(\mathrm{pr}<0,05)$.

\section{RESULTADOS E DISCUSSÃO}

As plântulas de Cassia grandis apresentaram diferenças significativas pelo teste $\mathrm{F}$ a $1 \%$ de probabilidade, para todas as variáveis analisadas, conforme verificado na Figura 1.

A não ocorrência de emergência no tratamento 11 foi, provavelmente, devido à quantidade de óleo presente na casca de castanha, ocasionando a queima das sementes e plântulas pelo ácido anacárdico, cuja composição no óleo é em torno de 70\% (AGOSTINI-COSTA et al., 2005). Outro fator para esse insucesso foi, também, provavelmente, o alto teor de matéria orgânica do composto (248 g. $\left.\mathrm{Kg}^{-1}\right)$ (Tabela 1). Foi observado por Sousa (2010), com sementes de Calotropis procera, que a emergência e o desenvolvimento inicial de plântulas foram prejudicados quando se utilizaram altas concentrações de composto orgânico. Da mesma forma, Nogueira et al. (2012), obtiveram resultados semelhantes com sementes de Mimosa caesalpiniifolia, cuja percentagem de emergência foi nula para os substratos com alto teor de matéria orgânica.

Os melhores resultados para emergência das plântulas de Cassia grandis foram encontrados nos tratamentos 9 e 13 (testemunha), mas não 
TABELA 1: Caracterização química e físicas dos substratos avaliados na emergência e desenvolvimento inicial de plântulas de Cassia grandis L. f., quanto a nitrogênio $(\mathrm{N}), \mathrm{pH}$, condutividade elétrica $(\mathrm{CE})$, teor de matéria orgânica $(\mathrm{MO})$, fósforo $(\mathrm{P})$, potássio $\left(\mathrm{K}^{+}\right)$, sódio $\left(\mathrm{Na}^{+}\right)$, cálcio $\left(\mathrm{Ca}^{+}\right)$, magnésio $\left(\mathrm{Mg}^{2+}\right)$, alumínio $\left(\mathrm{Al}^{3+}\right)$, porosidade total (PT) e densidade do substrato (DS). TABLE 1: Chemical and physical characterization of the tested substrates evaluated in the emergence and in the early development of Cassia grandis L. f., As nitrogen $(\mathrm{N}), \mathrm{pH}$, electrical conductivity $(\mathrm{EC})$, organic matter $(\mathrm{OM})$, phosphorus $(\mathrm{P})$, potassium $(\mathrm{K}+)$, sodium $(\mathrm{Na}+)$, calcium $(\mathrm{Ca}+)$, magnesium $\left(\mathrm{Mg}^{2}+\right)$, aluminum $\left(\mathrm{Al}^{3}+\right)$ total porosity $(\mathrm{TP})$ and substrate density $(\mathrm{SD})$.

\begin{tabular}{|c|c|c|c|c|c|c|c|c|c|c|c|c|}
\hline \multirow{2}{*}{ Trat } & \multirow{2}{*}{ DS } & \multirow{2}{*}{$\begin{array}{l}\text { PT } \\
\%\end{array}$} & \multirow{2}{*}{$\begin{array}{c}\mathrm{N} \\
\text { g.kg-1 }\end{array}$} & \multirow{2}{*}{$\begin{array}{c}\mathrm{pH} \\
\text { água }\end{array}$} & \multirow{2}{*}{$\begin{array}{c}\text { CE } \\
\text { ds. } m^{-1}\end{array}$} & \multirow{2}{*}{$\begin{array}{c}\mathrm{MO} \\
\text { g. } \mathrm{kg}^{-1}\end{array}$} & \multirow[t]{2}{*}{$P$} & $\mathrm{~K}^{+}$ & $\mathrm{Na}^{+}$ & \multirow{2}{*}{\multicolumn{3}{|c|}{ cmolc. $\mathrm{dm}^{-3}$}} \\
\hline & & & & & & & & $\mathrm{mg} \cdot \mathrm{dm}^{-3}$ & & & & \\
\hline 1 & 0,55 & 74,19 & 1,96 & 6,44 & 0,81 & 76,84 & 11,83 & 263,01 & 426,09 & 2,10 & 0,77 & 0,00 \\
\hline 2 & 0,40 & 78,01 & 0,42 & 6,38 & 0,76 & 80,77 & 209,23 & 968,86 & 483,16 & 1,40 & 1,30 & 0,00 \\
\hline 3 & 0,59 & 74,83 & 1,12 & 6,19 & 0,54 & 75,59 & 18,78 & 121,10 & 45,09 & 1,30 & 1,62 & 0,00 \\
\hline 4 & 0,44 & 80,33 & 1,12 & 5,18 & 0,20 & 101,39 & 59,43 & 1612,43 & 23,21 & 1,62 & 1,03 & 0,20 \\
\hline 5 & 0,51 & 77,97 & 0,70 & 6,46 & 0,27 & 84,03 & 7,21 & 242,25 & 2385,63 & 2,14 & 0,81 & 0,00 \\
\hline 6 & 0,62 & 73,54 & 0,98 & 6,43 & 0,22 & 78,28 & 99,55 & 104,50 & 540,24 & 1,88 & 1,21 & 0,00 \\
\hline 7 & 0,52 & 77,95 & 0,98 & 4,93 & 0,40 & 82,02 & 9,35 & 101 & 77, & 1,77 & 1,40 & 0,10 \\
\hline 8 & 0,25 & 89,52 & 1,40 & 4,34 & 0,43 & 96,69 & 112,93 & 657,45 & 426,09 & 2,30 & 1,35 & 0,50 \\
\hline 9 & 0,55 & 76,03 & 0,70 & 5,45 & 0,44 & 77,12 & 25,80 & 117,99 & 521,21 & 2,09 & 1,22 & 0,20 \\
\hline 10 & 0,44 & 80,14 & 1,12 & 4,19 & 0,41 & & 49,39 & 906,58 & 445,12 & 0,83 & 1,73 & 1,70 \\
\hline 11 & 0,43 & 80,86 & 2,24 & 5,00 & 0,57 & 248,57 & 4,74 & 283,77 & 426,09 & 0,73 & 2,41 & 1,85 \\
\hline 12 & 0,62 & 72,18 & 0,35 & 6,39 & 0,30 & 88,54 & 264,74 & 68,17 & 27,96 & 2,40 & 1,43 & 0,00 \\
\hline 13 & 0,72 & 70,35 & 0,70 & 6,62 & 0,17 & 71,08 & 5,54 & 65,05 & 273,89 & 2,03 & 1,12 & 0,00 \\
\hline
\end{tabular}

Em que: 1) terra vegetal + casca de arroz carbonizada (1:1);2) terra vegetal + casca de arroz carbonizada (1:3); 3) terra vegetal + casca de arroz carbonizada $(3: 1) ; 4)$ terra vegetal + pó de madeira $(1: 1) ; 5)$ terra vegetal + pó de madeira $(1: 3) ; 6)$ terra vegetal + pó de madeira $(3: 1) ; 7)$ terra vegetal + fibra de coco $(1: 1) ; 8)$ terra vegetal + fibra de coco (1:3); 9) terra vegetal + fibra de coco $(3: 1) ; 10)$ terra vegetal + casca de castanha $(1: 1) ; 11)$ terra vegetal + casca de castanha $(1: 3) ; 12)$ terra vegetal + casca de castanha (3:1) e 13) terra vegetal (testemunha).

diferiram estatisticamente dos tratamentos 4, 7 e 8. Apesar da testemunha ter tido resultado positivo, o bom resultado dos tratamentos $4,6,7$ e 8 foi atrelado à fibra de coco e ao pó de madeira, estando relacionado, provavelmente, com a grande capacidade de retenção de água que foi observada ao decorrer da pesquisa por esses compostos, fator esse considerado primordial nessa fase inicial de desenvolvimento. Segundo Bewley \& Black (1994), a embebição das sementes é o passo inicial para a sua germinação e deve ocorrer de forma contínua até que haja a emissão da radícula. Portanto, essa alta retenção de água no substrato proporcionou maior embebição pelas sementes. Nesse sentido, Pinto et al. (2011) obtiveram melhores resultados de emergências de plântulas de Mimosa caesalpiniifolia Benth., quando utilizaram como substrato a combinação de arisco e fibra de coco (1:1). Da mesma forma, Nogueira et al. (2012) também obtiveram altos valores de emergência em substratos compostos com fibra de coco pura, provavelmente, por apresentar maior capacidade de retenção de água. Alexandre et al. (2006), Wagner Junior et al. (2006) e Carrijo et al. (2002) destacaram que o substrato tem influência direta na emergência e desenvolvimento inicial das plântulas, e indicam a fibra de coco como alternativa viável para produção de mudas, por ser leve, de fácil manuseio, possuir boa capacidade de absorção de água e não exigir irrigação diária.

A velocidade de emergência de plântulas destacou-se para os tratamentos de 1 a 9, apresentando os melhores resultados e não diferindo estatisticamente entre si. Nesse parâmetro, ao contrário das demais, os menores valores são os melhores resultados, descartando-se apenas o tratamento 11, que resultou em percentual zero de emergência de plântulas (Figura 1B). Incluir o tratamento 2 - terra vegetal + casca de arroz carbonizada (1:3), pois não diferiu do 

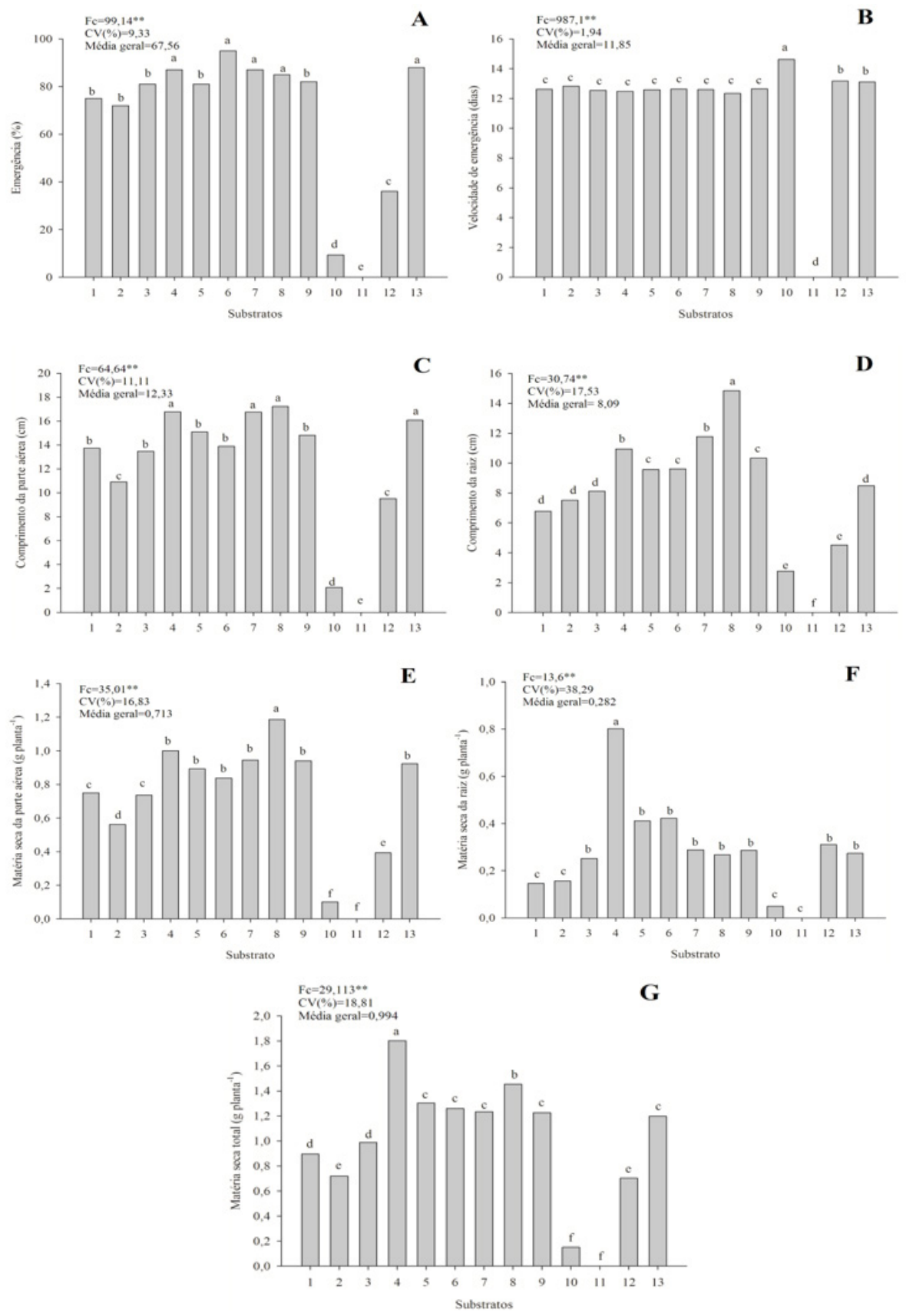

Em que: **Efeito significativo pelo teste $\mathrm{F}$ a $1 \%$ de probabilidade; Fc: $\mathrm{F}$ calculado; $\mathrm{CV}$ : coeficiente de variação.

FIGURA 1: Porcentagem de emergência (\%) de plântulas de Cassia grandis semeadas em diferentes substratos: 1) terra vegetal + casca de arroz carbonizada $(1: 1) ; 2)$ terra vegetal + casca de arroz carbonizada $(1: 3) ; 3)$ terra vegetal + casca de arroz carbonizada $(3: 1) ; 4)$ terra vegetal + pó de madeira $(1: 1) ; 5)$ terra vegetal + pó de madeira $(1: 3) ; 6)$ terra vegetal + pó de madeira $(3: 1) ; 7)$ terra vegetal + fibra de coco $(1: 1) ; 8)$ terra vegetal + fibra de coco $(1: 3) ; 9)$ terra vegetal + fibra de coco $(3: 1) ; 10)$ terra vegetal + casca de castanha $(1: 1) ; 11)$ terra vegetal + casca de castanha $(1: 3) ; 12)$ terra vegetal + casca de castanha $(3: 1)$ e 13$)$ terra vegetal (testemunha).

FIGURE 1: 1) plant sand + carbonized rice hull $(1: 1), 2)$ plant sand + carbonized rice hull (1:3), 3) plant sand + carbonized rice hull $(3: 1), 4)$ plant sand + wood dust $(1: 1), 5)$ plant sand + wood powder $(1: 3), 6)$ plant sand + wood powder $(3: 1), 7)$ plant sand + coconut fiber $(1: 1), 8)$ plant sand + coconut fiber $(1: 3)$; 9) plant sand + coconut fiber $(3: 1)$; 10) plant sand and bark chestnut $(1: 1), 11)$ plant sand + bark brown sand $(1: 3), 12)$ plant sand + bark chestnut (3:1) and 13) plant sand (control). 
tratamento 12 .

Essa estabilidade nos tratamentos de 1 a 9 se deu, pelo fato de as sementes terem sido embebidas em água por 24 horas, antes da semeadura, conforme recomendação de Carvalho Filho (2002). Com isso, observou-se que mesmo com esse período de embebição das sementes, os tratamentos 10, 11, 12 e 13 não se mostraram eficientes para promover o aumento da velocidade de emergência. Isso acontece por que as sementes ao serem semeadas já teriam completado total ou parcialmente a fase de embebição, como especificado por Adriance e Brison (1967).

No comprimento da parte aérea (Figura 1C), observam-se maiores resultados para as combinações de terra vegetal + fibra de coco (1:3), terra vegetal + pó de madeira $(1: 1)$, terra vegeta + fibra de coco (1:1) e testemunha (terra vegetal). Por outro lado, os valores mais baixos foram verificados para as combinações de terra vegetal + casca de castanha-de-caju nas três proporções estudadas e em terra vegetal + casca de arroz carbonizada (1:3). O mesmo foi verificado por Pacheco (2006), com sementes de Myracrodruon urundeuva, cujo resultado de comprimento da parte aérea se deu melhor em substrato de fibra de coco. Segundo o mesmo autor, esse fato está, provavelmente, relacionado à retenção de água encontrada nos substratos à base de fibra de coco e pó de madeira, característica que favorece o desenvolvimento da plântula, conforme observado nesse estudo para essa variável

A mistura de terra vegetal + fibra de coco (1:3) proporcionou maior comprimento da raiz (Figura 1D). Resultados semelhantes foram encontrados por Nogueira et al. (2012) e Pinto et al. (2011) com plântulas de Mimosa caesalpiniifolia Benth. A fibra de coco por sua alta porosidade e boa capacidade de retenção proporcionou melhor desenvolvimento, ocasionando maior crescimento da raiz principal em relação aos demais tratamentos. Com isso, houve aumento da profundidade de absorção, o que contribuiu para o sucesso desse substrato em relação aos demais.

O tratamento terra vegetal + fibra de coco (1:3), acarretou em uma produção de massa seca da parte aérea de $1,2 \mathrm{~g}_{\text {planta }}{ }^{-1}$. Por outro lado, os substratos que continham na sua composição casca de castanha-de-caju apresentaram resultados inferiores de massa seca da parte aérea em relação aos demais tratamentos. Portanto, ressalta-se o baixo potencial da casca de castanha-de-caju como substrato alternativo para produção de mudas (Figura 1E).

Os resultados de massa seca da parte aérea confirmam os encontrados por Nogueira et al. (2012), que obtiveram os maiores valores de massa seca de folhas e massa seca de caule de plântulas de Mimosa caesalpiniifolia, quando utilizaram o substrato fibra de coco. Resultados dessa variável estão relacionados com o comprimento da raiz que, também, foi maior no tratamento 8 , proporcionando maior acúmulo de biomassa seca na parte aérea.

Para a massa seca da raiz (Figura 1F), o substrato terra vegetal + pó de madeira (1:1) proporcionou melhores resultados no desenvolvimento das raízes secundárias e aumento da zona de absorção. Por outro lado, as combinações de terra vegetal + casca de castanha-de-caju (1:3 e $3: 1)$ resultaram nos piores valores para essa variável.

Os resultados superiores da massa seca da raiz verificados no tratamento 4 foram, provavelmente, atrelados às boas condições que o substratos ofereceu para o crescimento da raízes laterais, ocasionando um desenvolvimento satisfatório destas raízes e maior acúmulo de biomassa, apesar dos valores de menor comprimento da raiz principal.

O resultado de massa seca total (Figura $1 \mathrm{G}$ ) foi superior na combinação de terra vegetal + pó de madeira (1:1), isso foi ocasionado pelo maior acúmulo de massa seca da raiz proporcionada por esse tratamento, portanto, discordando dos dados de Nogueira et al. (2012), que obtiveram melhores resultados de massa seca total em fibra de coco. Isso reflete a qualidade física desses dois substratos, que apesar de possuírem qualidades químicas praticamente inertes, apresentam alta capacidade de retenção de água e boa aeração. Os piores valores foram encontrados na combinação de terra vegetal + casca de castanha-de-caju (1:1).

De forma geral, os resultados encontrados neste trabalho discordaram dos verificados por Neves et al. (2007), com sementes de moringa. Estes autores informaram que o substrato composto de areia e pó de madeira (3:1), proporcionou os menores valores para comprimento de raiz, altura de plântulas, índice de velocidade de germinação, porcentagem de germinação aos cinco e aos 19 dias após a germinação, peso de matéria fresca da plântula inteira e peso de matéria seca. Nesse mesmo sentido, constatou-se por Couto et al. (2002) para sementes de amoreira-preta, em que o pó de serra na proporção de 20 a $80 \%$ do substrato causou diminuição no comprimento das raízes 
quando comparado aos outros tratamentos. Esses mesmos autores, ainda, verificaram que o aumento da proporção de pó de serra na composição do substrato acarretou diminuição linear dos valores para quase todas as variáveis analisadas, apesar desses autores usarem proporções diferentes de substratos, os resultados foram atrelados ao uso do pó de madeira independentemente da proporção. Segundo Fachinello et al. (1995), existe uma série de resíduos tóxicos provenientes do pó de origem da madeira, que podem afetar a germinação; portanto, recomenda-se, diversas lavagens com água corrente para eliminação desses resíduos do substrato. No tocante a esse trabalho, o procedimento utilizado para o uso do pó de madeira curtido foi a exposição ao sol por 40 dias e irrigação diária, procedimento que se mostrou eficiente em razão dos resultados obtidos para os substratos que continham esse composto.

\section{CONCLUSÕES}

Os substratos terra vegetal + pó de madeira $(1: 1)$ e terra vegetal + fibra de coco (1:3) mostramse superiores aos demais, proporcionando melhores resultados em emergência, massa seca da parte aérea, comprimento da parte aérea, massa seca da raiz e comprimento da raiz.

O substrato composto de terra vegetal + castanha-de-caju (1:3) não favoreceu a germinação de sementes de Cassia grandis.

\section{REFERÊNCIAS BIBLIOGRÁFICAS}

ADRIANCE, G. W.; BRISON, F. R. Propagation of horticultural plants. 2.ed. Bombay Tata: McGrawHill, 1967. 289 p.

AGOSTINI-COSTA, T. S. et al. Determinação espectrofotométrica de ácido anacárdico em amêndoas de castanha de caju. Brasília: Embrapa Recursos Genéticos e Biotecnologia, 2005. 10 p. (Comunicado Técnico, 122).

ALEXANDRE, R. S. et al. Estádio de maturação dos frutos e substratos na germinação de sementes e desenvolvimento inicial de plântulas de jabuticabeira. Revista Brasileira de Agrociência, v.12, n.2, p. 227-230, 2006.

ALMEIDA, J. P. N. et al. Composição de substratos alternativos com capítulo de girassol na produção de mudas de mamoeiro. Revista Verde de Agroecologia e Desenvolvimento Sustentável, v.6, n.1, p.174-178, 2011.
ARAÚJO, A. P.; PAIVA SOBRINHO, S. Germinação e produção de mudas de tamboril (Enterolobium contortisiliquum (Vell.) Morong) em diferentes substratos. Revista Árvore, v.35, n.3, p.581-588, 2011.

BEWLEY, J. D; BLACK, M. Seeds: physiology of development and germination. New York: Plenum, 1994. 445p.

BRASIL. Ministério da Agricultura, Pecuária e Abastecimento. Regras para análise de sementes. Brasília: Ministério da Agricultura e Reforma Agrária, 2009. 399p.

CÁCERES, A. et al. Plants used in Guatemala for treatement of dermatphytic inctions. Jornal of Ethonopharmacology, v.31, p.263-76, 1995.

CARRIJO, O. A.; LIZ, R. S.; MAKISHIMA, N. Fibra da casca do coco verde como substrato agrícola. Horticultura Brasileira, v.20, n.4, p.533-535, 2002.

CORREIA, D. et al. Efeito de substratos na formação de porta-enxertos de psidium guajava L. cv. ogawa em tubetes. Revista Brasileira de Fruticultura, v.27, n.1, p. 88-91, 2005.

COUTO, M. et al. Avaliação do pó-de-Serra como substrato para a aclimatização da amoreira preta (Rubus spp.) cultivar Tupy em Casa de Vegetação. In:XVI CONGRESSO BRASILEIRO DE FRUCULTURA,2002, Belém. CD-ROMXVIICBF. Belém-Pára: www.mpdesing.myw.com. br, 2002.

EDMOND, J. B.; DRAPALA, W. J. The effects of temperature, sandand soil, and acetone on germination of okra seeds. Proceedings of American Society of Horticultural Science, v.71, n.2, p.428-434, 1958.

FACHINELLO, J. C. et al. Propagação de plantas frutíferas de clima temperado. 2. ed. Pelotas: UFPEL, 1995. 178p.

FERREIRA，D. F. SISVAR: um programa para análises e ensino de estatística. Revista Symposium, v.6, n.2, p.36-41, 2008.

LORENZI, H. Árvores brasileiras: manual de identificação e cultivo de plantas arbóreas nativas do Brasil. 5 ed. Nova Odessa: Ed. Plantarum Ltda., 2008. 384p.

MORAES NETO, S. P. et al. Produção de mudas de espécies arbóreas nativas com combinações de adubos de liberação controlada e prontamente solúveis. Revista Árvore, v.27, n.6, p.779-789, 2003.

NEVES, N. N. A. et al. Germinação de sementes e desenvolvimento de plântulas de Moringa oleifera 
Lam. Revista Caatinga, v.20, n.2, p.63-67, 2007. NOGUEIRA, N. W. et al. Emergência e desenvolvimento inicial de plântulas de Mimosa caesalpiniifolia Benth. em função de diferentes substratos. Revista Agroambiente, v.6, n.1, p.17-24, 2012.

PACHECO, M. V. et al. Efeito de temperaturas e substratos na germinação de sementes de Myracrodruon urundeuva Fr. All. (anacardiaceae), Revista Árvore, v.30, n.3, p. 359-367, 2006.

PINTO, J.R. S. et al. Diferentes tipos de substratos no desenvolvimento inicial de Mimosa caesalpiniifolia Benth. Revista Verde de Agroecologia e Desenvolvimento Sustentável, v.6, n.3, p.180-185, 2011.
SAIDELLES, F. L. F. et al. Casca de arroz carbonizada como substrato para produção de mudas de tamboril-da-mata e garapeira. Semina: Ciências Agrárias, v.30, suplemento 1, p.1173-1186, 2009. SOUZA, D. C. F. Crescimento e desenvolvimento inicial de plântulas de flor de seda (Calotropis procera) em diferentes substratos. 2010. 32f. Monografia (Graduação em Agronomia) - Universidade Federal Rural do Semi-Árido, Mossoró, 2010.

WAGNER JUNIOR, A. et al. Influência do substrato na germinação e desenvolvimento inicial de plantas de maracujazeiro amarelo (Passiflora edulis Sims f. flavicarpa Deg). Ciência e Agrotecnologia, v. 30, n.4, p.643-647, 2006. 